\title{
Towards an Outpatient Model of Care for Motor Functional Neurological Disorders: A Neuropsychiatric Perspective
}

This article was published in the following Dove Press journal:

Neuropsychiatric Disease and Treatment

\author{
Aneeta Saxena ${ }^{1,2}$ \\ Ellen Godena' \\ Julie Maggio ${ }^{1,3}$ \\ David L Perez (D) $)^{1,4}$
}

'Functional Neurological Disorder Clinical and Research Program, Cognitive Behavioral Neurology Unit, Department of Neurology, Massachusetts General Hospital, Harvard Medical School, Boston, MA, USA; ${ }^{2}$ Epilepsy Division, Department of Neurology, Boston Medical Center, Boston University School of Medicine, Boston, MA, USA;

${ }^{3}$ Department of Physical Therapy, Massachusetts General Hospital, Boston, MA, USA; ${ }^{4}$ Division of Neuropsychiatry, Massachusetts General Hospital, Harvard Medical School, Boston, MA, USA
Correspondence: Aneeta Saxena Massachusetts General Hospital, Department of Neurology, 55 Fruit Street, Boston, MA 02114, USA Email asaxena7@mgh.harvard.edu

\begin{abstract}
Functional neurological disorder (FND), a condition at the intersection of neurology and psychiatry, is a common and disabling outpatient referral to neurology and neuropsychiatry clinics. In this perspective article, we focus on the motor spectrum of FND (mFND), including individuals with functional movement disorders (FND-movt), functional limb weakness/paresis (FND-par) and functional [psychogenic non-epileptic/dissociative] seizures (FND-seiz). Over the past several decades, there have been dedicated efforts within the neurologic and psychiatric communities to create "rule-in" diagnostic criteria, as well as thoughtful approaches to the clinical interview, delivery of the diagnosis and the development of a patient-centered treatment plan. These advances allow the promotion of good clinical practices in the outpatient assessment and management of mFND. Informed by the literature and our prior clinical experiences, we provide suggestions on how to evaluate individuals with suspected functional motor symptoms - including conducting sensitive psychiatric and psychosocial screenings. Additional sections discuss common "rule-in" neurological examination and semiologic signs of motor FND, as well as approaches to deliver the diagnosis and formulate a treatment plan based on individual patient needs. To aid the development of shared (partially overlapping) expertise that catalyzes an interdisciplinary approach to mFND, the use of physiotherapy for therapeutic motor retraining and cognitive behavioral therapy to examine relationships between symptoms, thoughts, behaviors and emotions are also discussed. Additional clinical research is needed to further refine and operationalize the assessment and management of mFND, across clinics, healthcare settings and countries.
\end{abstract}

Keywords: functional movement disorder, dissociative seizures, conversion disorder, psychogenic, treatment, neuropsychiatry

\section{Introduction}

Functional Neurological Disorder (FND), a condition at the intersection of neurology and psychiatry, is common in outpatient neurology and neuropsychiatry clinics. $^{1,2}$ With the changes made in the Diagnostic and Statistical Manual of Mental Disorders, Fifth Edition (DSM-5), positive examination signs and semiological features enabled a "rule-in" FND diagnosis. ${ }^{3}$ This article focuses on the spectrum of motor FND (mFND), including functional movement disorders (FNDmovt), functional limb weakness/paresis (FND-par) and functional [psychogenic non-epileptic/dissociative] seizures (FND-seiz). ${ }^{4}$ A transdiagnostic approach across functional motor disorders is supported by observations that many patients present 
with mixed symptoms or exhibit one symptom complex initially and subsequently develop distinct symptoms during their illness. ${ }^{5,6}$ Patients can also experience disabling pain, fatigue, and cognitive clouding, along with psychiatric comorbidities and psychosocial difficulties that warrant consideration when developing a patient-centered treatment plan. ${ }^{7-10}$ For patients with FND-seiz, increased diagnostic certainty can be obtained using videoelectroencephalography (EEG), ${ }^{11,12}$ while challenging FND-movt cases can potentially benefit from adjunctive electromyography (EMG) to aid detection of functional motor features. ${ }^{13,14}$ In parallel with a more uniform diagnostic approach is the emergence of evidence-based treatments spanning motor rehabilitation and psychotherapy. ${ }^{15-}$ 18 These advances set the stage for the dissemination of good clinical practices in the outpatient assessment and management of mFND.

Our goal in this article is to provide a practical guide for the neuropsychiatric approach to the outpatient assessment and management of mFND. ${ }^{12,14,19,20} \mathrm{We}$ have previously detailed our viewpoint on assessment and management strategies in the acute hospital and emergency department settings. ${ }^{21,22}$ Here, we provide a framework for the initial assessment and management of mFND modeled in part after the example of the Massachusetts General Hospital FND Clinic. ${ }^{6,23-26}$ Using the approach detailed below, Glass et al previously reported in 81 consecutive patients with at least one follow-up that $42 \%$ noted some degree of clinical improvement at 7 months. ${ }^{23}$ While emphasis on neurological examination and semiological features aids the neurologist's role in diagnosis, a comprehensive assessment guiding the development of a patientcentered treatment plan benefits from interdisciplinary neurologic, psychiatric, allied mental health and rehabilitation perspectives. ${ }^{14}$ Sections of this article outline the neuropsychiatric history, physical examination, delivery of the diagnosis, treatment planning, physical rehabilitation, and psychological treatments. Lastly, we discuss the physician's role in longitudinal follow-up. ${ }^{27,28}$ While recent publications have suggested that specialized FND clinics should be integrated within neurology departments to aid patient care (a sentiment we support), ${ }^{29}$ high prevalence rates suggest that both specialized tertiary care centers and community-based care will be needed to meet the needs of this prevalent patient population. As such, clinicians across the clinical neurosciences should develop proficiency in the outpatient assessment and management of mFND. ${ }^{30}$ The approach put further below is one example of good outpatient practices, however, as research expands optimal approaches will be further refined.

\section{Framing the Encounter}

It is first important to operationalize the context for the outpatient clinical encounter. The approach put forth here is for patients that are referred by another physician (typically a neurologist or other physician who has performed an initial neurological evaluation) for a suspected diagnosis of mFND. Thus, there is already an index of suspicion for functional neurological symptoms. Within this context, goals of the initial assessment would include diagnostic confirmation, as well as performing a neuropsychiatric interview (psychiatric and psychosocial screenings) to inform discussions regarding delivery of the diagnosis and treatment planning. Given that evaluating mFND patients can take more time than other neurological consultations, consideration should be given to setting aside at least 1 hour if possible. In our clinical program, we aim for a 90-minute initial visit. Given a variety of different time constraints (e.g., clinic workflows, healthcare policy, an FND-seiz event ect) it may not be possible to complete the initial assessment in one visit. As such, relevant information can be gathered over a series of visits. Additionally, reviewing available medical records beforehand can aid time efficiency. Lastly, our perspective cultivates an element of shared (partially overlapping) expertise across neurology, psychiatry and allied rehabilitation disciplines. ${ }^{31}$ For a suspected mFND referral, neurologists working at this interface should develop increased proficiency in psychiatric and psychosocial screenings, while psychiatrists should have increased neurological training to accurately elicit neurological "rule-in" signs guiding an mFND diagnosis.

\section{Neuropsychiatric Interview}

The interview of individuals suspected of mFND aids the diagnostic assessment and can be therapeutic. The clinical interview is an opportunity to understand the complexity and natural history of the symptom complex, the patient's illness perception, and a range of other medical, neurologic, psychiatric, and psychosocial factors that inform treatment planning. ${ }^{12,14}$ 


\section{Chief Complaint and Other Physical Symptoms}

Unpacking the chief complaint starts with evaluating the sensorimotor symptoms of concern: 1) timing and acuity of events (e.g., sudden onset vs insidious onset); 2) debilitating at onset or slowly progressive; 3) evolution of symptoms over time (e.g., spontaneous resolutions); 4) range of symptoms experienced; and 5) chronic or paroxysmal. ${ }^{14}$ While the history is non-specific for mFND, clues can include maximal severity in a short time window and the presence of spontaneous resolutions. ${ }^{14}$ For those with paroxysmal symptoms, inquiring about prodromal or warning symptoms (including physiological panic without the accompanying negative affect (panic without panic)) will provide useful information that may increase patient's awareness of such instances. ${ }^{32}$ In our experience, warning or build-up type symptoms are infrequently endorsed spontaneously unless a specific inquiry is made. Similarly, asking about triggers can also be helpful. There is increasing awareness that physical injury (e.g., traumatic brain injury, peripheral limb injury), in addition to emotionally-valenced events, can be associated with mFND. ${ }^{33,34}$ Inquiring about triggers should not be limited to symptom onset, as patients will commonly report that sensory experiences (bright lights, loud sounds) may trigger or amplify symptoms chronically. ${ }^{35}$ The presentation of mixed symptoms is common, underscoring that while the patient may primarily report one neurological symptom (e.g., seizures) asking about the range of possible neurological symptoms (including cognitive symptoms) is important. ${ }^{10,36,37}$ This can also prevent questions about unaddressed symptoms at the end of the visit. ${ }^{19,20}$ Lastly, the clinician should also listen for symptoms that potentially raise concern for other neurological/medical conditions, particularly given that neurological comorbidities are common in patients with mFND. For example, $20 \%$ of patients with FND-seiz also have concurrent epileptic seizures ${ }^{38}$ and a subset of patient's with Parkinson disease also exhibit mFND features. ${ }^{39}$ Lastly it is important to consider how the patient understands their symptoms. Illness beliefs such as thoughts that symptoms will be permanent can be poor predictors of outcome. ${ }^{40}$

Other symptoms such as pain, fatigue, insomnia, bowel and/or bladder difficulties should also be screened for. Asking about functional somatic diagnoses (e.g., fibromyalgia, irritable bowel syndrome, ect) can be another way of contextualizing bodily concerns. Understanding patients medical and surgical histories, experiences with healthcare professionals, medication use, allergies and family history across medical/neurological/psychiatric diagnoses is also helpful. For example, a greater number of medication allergies/intolerances is more common in mFND than other neurological populations and may be a marker of somatic hypervigilance. ${ }^{6,41}$ Once the clinician feels that there is an initial good understanding of the patient's physical symptoms, they can transition to performing psychiatric and psychosocial screenings. Focused psychiatric and psychosocial screenings should be performed early in the interview (prior to the physical examination) to avoid explicit connection to the delivery of the diagnosis, which can prove invalidating and negatively impact acceptance of the diagnosis. ${ }^{42}$

\section{Psychiatric Screening}

High rates of psychiatric comorbidities (categorically and dimensionally) are present in patients with mFND. ${ }^{8,12,14,43-45}$ Assuming sufficient time to ask sensitively, the psychiatric screen should include assessing current and past depression, anxiety, trauma-related symptoms, self-injurious behaviors, suicidality, past psychiatric hospitalizations, and prior mental health treatment including psychotherapy such as cognitive behavior therapy (CBT). It can be helpful to explicitly state: "Let's shift topics and talk about the emotional side of things. Would that be okay?". If the interviewer senses resistance or concern from the patient you can reassure them by noting "These are questions that we ask all patients that come through our clinic and these questions may or may not be relevant to you". Within the context of inquiring about depression episodes (or chronic low-grade depression suggestive of dysthymia), it is important to ask about dysphoric (negative) mood as well as diminished pleasure in activities (anhedonia). Similarly, the spectrum of anxiety and trauma-related disorders should be assessed. This can be introduced by asking the patient if they "are a worrier" or "struggle with worries". Exploring multi-content fears (including health anxiety) can aid understanding if the patient has a generalized anxiety disorder or an illness anxiety disorder. ${ }^{46}$ Asking about panic attacks should include whether events are triggered or untriggered and the presence of agoraphobia. As noted above, paroxysmal mFND features may overlap with some panic attack symptoms. Inquiring sensitively about traumatic experiences (including childhood maltreatment, as well as adverse experiences as an adult) can facilitate an inquiry into lifetime PTSD symptoms related to hypervigilance, intrusive traumatic 
recollections, nightmares, and dissociation. ${ }^{47}$ It can be helpful to tell the patient that "We do not need to unpackage the events in any great detail" to aid sensitive discussions. While high rates of lifetime PTSD symptoms are described in mFND, many will not have active PTSD at the time of the assessment but residual hypervigilance or avoidance tendencies may be present. ${ }^{44}$ Asking about estrangement or disconnection from one's body or surroundings can also evaluate dissociation. ${ }^{48,49}$ Completing the psychiatric screen with open ended questions regarding "How do you deal with life stress" and inquiring about interpersonal relationships can also prove useful. Some patients may have difficulty answering questions about mood or anxiety, even asking the interviewer "I'm not sure what you mean by depression". These may be clues suggesting alexithymia (having difficulty putting emotions into words). ${ }^{50}$ When considering psychopathological traits, be mindful to listen for obsessive-compulsive or neurotic tendencies. ${ }^{50}$ Lastly, briefly inquiring about eating disorders, mania/hypomania, obsessions/compulsions and psychotic spectrum illness help complete the interview. While it is rare for patients with psychosis to have mFND, some with psychotic spectrum disorders can be somatically preoccupied and this is important to consider on the differential diagnosis. We have encountered several young adults in the prodromal or early stages of psychotic spectrum illness referred to the FND clinic that did not meet criteria for FND but had significant bodily (somatic) concerns.

\section{Psychosocial Screen}

Psychosocial factors are important predisposing vulnerabilities, acute precipitants and/or perpetuating factors for mFND within the biopsychosocial model (See Table 1). ${ }^{21}$ The clinician should decide based on the natural flow of the encounter whether it makes more sense to first conduct the psychiatric screen or if it may be more beneficial to begin with the psychosocial history. We have found that asking "What was life like for you growing up" as a helpful way to begin this conversation. This can facilitate a discussion about early home life and relationships with family members. For some this can also be a natural transition to discussing early-life adversity. ${ }^{51}$ Education and work histories are important, including whether the patient is on or applying for disability and if there are any financial or legal concerns. Asking about interpersonal relationships can also provide rich content, including any marital difficulties or other family tensions. ${ }^{52}$ Cultural and religious factors may also be relevant, including an overlap between paroxysmal mFND and "ataque de nervios" described in some Latin American cultures. ${ }^{53}$ Alcohol and illicit drug misuse histories should also be screened for either during the psychosocial or psychiatric screen. Lastly, it is helpful to ask about how an individual spends their weekdays as well as inquiring about hobbies and social supports. ${ }^{54,55}$

\section{"Rule-in" Examination Signs}

"Rule-in" neurological examination signs and semiological features have been detailed in several authoritative reviews, with high yield features outlined in Table $2 .^{56-61}$ Signs specific for functional limb weakness include Hoover's sign, hip abductor sign, collapsing/giveway weakness and motor inconsistency among other signs. ${ }^{58}$ When collapsing/giveway weakness is appreciated on confrontation testing, asking about pain is important as "pain limited weakness" should not be confused for functional limb weakness. Hyperactivation of the platysma with jaw deviation is a sign of functional facial weakness. $^{62}$ For the range of FND-movt, familiarity with the typical movement disorder presentations aids diagnosis by noting features that are inconsistent and incongruent with other movement disorders. ${ }^{56}$ For functional tremor, variability and distractibility are hallmark features, with motor and cognitive tasks commonly used for distraction. Tremor entrainment (the hijacking of the functional tremor rhythm by volitional movements performed elsewhere in the body) is another specific sign for FND-movt. Functional gait disorders can present with a range of features, including non-economical compensatory movements (astasia-abasia), dragging monoplegic gait, fear of falling gait, and sudden knee buckling among other presentations. ${ }^{60}$ Appreciating motor inconsistency in these various presentations aids diagnosis (e.g., walking normally to go to the bathroom and yet exhibiting a markedly impaired gait with non-economical compensatory movements when attention is drawn to the patient's gait during examination); the chair test (maneuvering a rolling chair well from a seated position out of proportion to apparent gait difficulties) is another specific functional motor sign. ${ }^{63}$ Excellent teaching videos demonstrating a range of functional motor signs have been published and are high yield educational resources. $^{60,64-66}$ When features suggestive of mFND are appreciated, it can be helpful to show these to the patient; the examiner can also refer back to these signs during delivery of the diagnosis (see below). ${ }^{67}$ Caution should be taken to not mistakenly jump to conclusions in 
Table I The Biopsychosocial Model: Predisposing, Precipitating and Perpetuating Factors for the Development and Maintenance of Motor Functional Neurological Disorders

\begin{tabular}{|c|c|c|c|}
\hline & Biological & Psychological & Psychosocial \\
\hline $\begin{array}{l}\text { Predisposing } \\
\text { Vulnerabilities }\end{array}$ & $\begin{array}{l}\text { - Sex - female (except for military/veteran cohorts) } \\
\text { - Intellectual disability } \\
\text { - Comorbid neurological conditions } \\
\text { - Other nervous system vulnerabilities } \\
\text { - Co-morbid functional somatic disorders (i.e., } \\
\text { fibromyalgia, irritable bowel syndrome, other } \\
\text { chronic pain disorders) } \\
\text { - Sensory processing difficulties }\end{array}$ & $\begin{array}{l}\text { - Mood and anxiety disorders, PTSD, per- } \\
\text { - } \text { sonality disorders } \\
\text { - } \text { Alexsociation } \\
\text { - Insecure attachment } \\
\text { - Temperament and maladaptive person- } \\
\text { ality traits (i.e., obsessive-compulsive, } \\
\text { neuroticism) }\end{array}$ & $\begin{array}{l}\text { - Family functioning } \\
\text { - Chronic illness in family } \\
\text { - Traumatic death in } \\
\text { family } \\
\text { - Adverse life experiences } \\
\text { - Financial status } \\
\text { - Inadequate social } \\
\text { support }\end{array}$ \\
\hline $\begin{array}{l}\text { Precipitating } \\
\text { Factors }\end{array}$ & $\begin{array}{l}\text { - Abnormal physiological event(s), such as sleep } \\
\text { - deprivation, hyperventilation, palpitations } \\
\text { - Acute physical pain } \\
\text { - Peripheral limb injury or head trauma } \\
\text { - Surginess caused by vestibular event } \\
\text { - Suntervention }\end{array}$ & $\begin{array}{l}\text { - Emotional reactions to physical injury } \\
\text { or other life events } \\
\text { - Acute dissociative event } \\
\text { - Panic attack (including dizziness as part } \\
\text { of panic) }\end{array}$ & $\begin{array}{l}\text { - Loss of employment or } \\
\text { other occupational } \\
\text { difficulty } \\
\text { - Divorce or marital } \\
\text { strain } \\
\text { - Traumatic death of } \\
\text { loved one } \\
\text { - Other relational stress }\end{array}$ \\
\hline $\begin{array}{l}\text { Perpetuating } \\
\text { Factors }\end{array}$ & $\begin{array}{l}\text { - Physiological arousal } \\
\text { - Chronic pain } \\
\text { - Chronic fatigue } \\
\text { - Abnormal motor habit formation } \\
\text { - Deconditioning } \\
\text { - Other medical/neurological comorbidities limiting } \\
\text { treatment participation }\end{array}$ & $\begin{array}{l}\text { - Negative expectation bias } \\
\text { - Negative attentional bias } \\
\text { - Illness beliefs including perception of } \\
\text { symptom irreversibility or attribution } \\
\text { - to another cause } \\
\text { - "Near of falling } \\
\text { - Avo pain no gain" philosophy to healing } \\
\text { - Hypervigilance and dissociation } \\
\text { - Identity linked to rigid concepts around } \\
\text { self-control, productivity, self-efficacy }\end{array}$ & $\begin{array}{l}\text { - Provider diagnostic } \\
\text { uncertainty } \\
\text { - Social benefits of being } \\
\text { ill (often out of } \\
\text { awareness) } \\
\text { - Pending litigation } \\
\text { - Workmen's compensa- } \\
\text { tion/disability } \\
\text { - Poor care coordination } \\
\text { - Poor family buy in/sup- } \\
\text { port of diagnosis and } \\
\text { treatment plan } \\
\text { - Employer or patient } \\
\text { urgency to return to } \\
\text { work }\end{array}$ \\
\hline
\end{tabular}

Notes: The above list is not exhaustive but rather is representative of the commonly encountered factors that are relevant to consider in developing a patient-oriented biopsychosocial formulation. A given factor may also cut across categories; for example, alexithymia can be both a predisposing vulnerability and a perpetuating factor. Adapted from Psychosomatics. 59(4). McKee K, Glass S, Adams C, et al. The inpatient assessment and management of motor functional neurological disorders: an interdisciplinary perspective. 358-368, copyright (2018), with permission from Elsevier. ${ }^{21}$

labeling bizarre never previously seen neurological presentations for functional, as well as confusing the difficult to examine patient because of behavior/affect for a mFND presentation. ${ }^{68}$ Marginally positive functional signs should also be interpreted with caution.

For FND-seiz, semiological features differentiating functional vs epileptic seizures include tight eye closure at event onset, ictal crying, asynchronous side to side head or body movements, lack of post-ictal period and long duration events among others. ${ }^{59,69}$ Notably, urinary incontinence and tongue biting are nonspecific, although tip of the tongue biting events may be more suggestive of FND- seiz while lateral tongue lacerations are consistent with epileptic generalized tonic clonic seizures. ${ }^{70}$

While the diagnosis of FND-movt and FND-par are made by physical examination, review of semiological features can be complemented by capturing a typical event(s) on videoEEG to make a diagnosis of "documented" FND-seiz. ${ }^{11}$ Notably, electromyography can aid the diagnosis of some FND-movt presentations (e.g., identification of variable and increased latencies in functional myoclonus; electrophysiological evidence of tremor pause with contralateral movements). ${ }^{13,14}$ However, these procedures are limited by their availability, as for example these tests are not currently 
Table 2 Examples of "Rule-in" Neurological Examination Signs and Semiological Features Guiding the Diagnosis of Motor Functional Neurological Disorders

\begin{tabular}{|c|c|}
\hline Functional Neurological Sign & Description \\
\hline \multicolumn{2}{|l|}{ Functional Limb and Face Weakness } \\
\hline Hoover's Sign & $\begin{array}{l}\text { Patient seated; place hand under paretic thigh and ask patient to push down - he/she cannot; } \\
\text { now ask patient to flex contralateral/normal leg up against resistance; test is positive if there is } \\
\text { now strong downward pressure in paretic leg. May also be performed in supine position. }\end{array}$ \\
\hline Hip Abductor Sign & $\begin{array}{l}\text { In a seated position, ask patient to abduct weak leg verifying apparent weakness. Thereafter, test } \\
\text { bilateral hip abduction strength and if there is now good bilateral hip abduction strength, the test } \\
\text { is positive. }\end{array}$ \\
\hline Collapsing/Give-way Weakness & $\begin{array}{l}\text { Full strength briefly evident on exam, but limb collapses from normal position thereafter; strength } \\
\text { suddenly gives way to collapse during testing. Caution in interpreting this sign in the presence of } \\
\text { pain (which may be more suggestive of pain-limited weakness). }\end{array}$ \\
\hline Motor Inconsistency & $\begin{array}{l}\text { Motor performance of a muscle or muscle group varies between two tests (e.g., unable to flex leg } \\
\text { on confrontation testing but readily able to left leg when putting themselves in bed or putting on } \\
\text { their shoes). }\end{array}$ \\
\hline Hemifacial Overactivity & $\begin{array}{l}\text { Jaw deviation, platysma hyperactivation and/or orbicularis oculi contraction; superficially } \\
\text { resembles an upper motor neuron pattern for facial weakness. }\end{array}$ \\
\hline \multicolumn{2}{|l|}{ Functional Movement Disorders } \\
\hline Tremor variability/distractibility & $\begin{array}{l}\text { Marked variability in frequency, rhythmicity and semiology of movements; improvement, pauses } \\
\text { or complete tremor resolution with distraction (can be a cognitive or motor tasks). }\end{array}$ \\
\hline Tremor Entrainment & $\begin{array}{l}\text { Functional tremor adopts rhythmicity of paced volitional movements performed elsewhere in the } \\
\text { body (can be demonstrated via finger tapping or hand opening/closing). }\end{array}$ \\
\hline Sudden Knee buckling & $\begin{array}{l}\text { Knees buckle with standing or ambulation, rarely leading to falls; sign can also be coupled with } \\
\text { motor inconsistency such as a lack of knee buckling on backward tandem gait. }\end{array}$ \\
\hline Non-economical gait (Astasia-abasia) & $\begin{array}{l}\text { Markedly exaggerated compensatory and uneconomical movements, often with flailing arms or } \\
\text { trunk appearing to be unstable; however, compensatory maneuvers demonstrate significant } \\
\text { preserved coordination. }\end{array}$ \\
\hline Dragging Monoplegic Gait & $\begin{array}{l}\text { Patient with unilateral leg weakness drags leg behind them like inanimate object, often with } \\
\text { externally rotated foot. }\end{array}$ \\
\hline \multicolumn{2}{|l|}{$\begin{array}{l}\text { Functional [Psychogenic Nonepileptic I } \\
\text { Dissociative] Seizures }\end{array}$} \\
\hline Long duration & Duration over 2 minutes. Use with caution, as alternative is status epilepticus. \\
\hline Fluctuating course & Intervening pauses, waxing/waning event tempo. \\
\hline Specific ictal movements or characteristics & $\begin{array}{l}\text { Asynchronous or side-to-side movements, pelvic thrusting (can also be seen in frontal lobe } \\
\text { seizures), ictal crying. }\end{array}$ \\
\hline Forced eye closure & Often against resistance of examiner. \\
\hline Increased ictal awareness & Post-ictal recall of information presented ictally. \\
\hline Post-ictal features & Absence of post-seizure confusion. \\
\hline Response to external stimuli & Bystanders may be able to alleviate or intensify the ictal event. \\
\hline
\end{tabular}

Notes: Adapted from Psychosomatics. 59(4). McKee K, Glass S, Adams C, et al. The inpatient assessment and management of motor functional neurological disorders: an interdisciplinary perspective. 358-368, copyright (2018), with permission from Elsevier. ${ }^{21,69}$

available in our center. Lastly, while clinical neuroimaging is not useful to "rule-in" an mFND diagnosis, FND can co-exist with other neurological conditions; clinicians should have a low threshold to acquire scans as otherwise appropriate. It can also be helpful to discuss with patients prior to ordering neuroimaging tests the potential identification of incidental or nonspecific findings that may not relate to their mFND symptom complex, such as the identification of non-specific T2 hyperintensities in patients with migraine headaches. ${ }^{71}$ Additionally, for prominent physical comorbidities (e.g., pain, fatigue), these symptoms should be appropriately (though not necessarily exhaustively) worked up to ensure that there is not a readily identifiable cause (e.g., obstructive sleep apnea). 


\section{Delivering the Diagnosis and Next Steps}

Delivering the diagnosis of FND is the first step in treatment. ${ }^{72}$ Understanding the diagnosis can in a small minority lead to symptom resolution, ${ }^{73}$ and acceptance of the diagnosis is important in aiding treatment engagement. ${ }^{74}$ Successful delivery of the diagnosis relies upon principles of validation, clarity regarding the rationale for the diagnosis, providing a diagnostic label, referencing a conceptual model (software vs hardware problem; mind-body overload), providing educational materials and establishing plans for follow-up appointments. $^{42,75}$ Pictorial illustrations demonstrating useful approaches to the delivery of the diagnosis and follow-up discussions have been published and are helpful educational resources. ${ }^{28,42}$

Naming the diagnosis can be perceived as challenging by the neurologist given concerns of losing the patient's trust or harming the therapeutic alliance. ${ }^{75,76}$ Similar to the delivery of the diagnosis in other neurologic conditions, rather than leading with discussion of normal test results and comments regarding conditions that are not present, the clinician can simply state "Based on your history and exam (including those signs that I showed you earlier), you have a Functional Neurological Disorder". The specific type of FND can also be introduced such as a functional gait disorder or FND-seiz. Asking if the patient has ever heard of this condition can be a natural segue into providing educational materials on websites such as www.neurosymptoms.org or www.fndhope.org. In our program, we try to give patients a brief 2-3 minute "walk through" of www.neurosymptoms.org as well as printed educational materials for the patient to go home with. We emphasize that the patient learning about FND and being curious about the diagnosis is an important early treatment step. It is also important to involve family members and other care providers to ensure that they understand the rationale behind the diagnosis and have an opportunity themselves to ask questions and raise any concerns.

Validating the patient's symptoms occurs by explaining that FND is common, real and brain-based disorder, and that the condition can be diagnosed by neurological signs. A provider believing the disorder is brain-based (at the intersection of neurology and psychiatry) and avoiding subconscious biases that FND is "all psychological" are important. ${ }^{77-79}$ Unless the patient is already making the connections explicitly for themselves, avoid creating a direct relationship between "stress" and the diagnosis of FND at the initial visit; connections between acute and chronic stress have indirect (yet important) relationships with FND that are nuanced. ${ }^{51}$ It can also be helpful to focus initially on "what" the diagnosis is based on examination and that the "why" is individualized and can be explored through physical rehabilitation and psychological treatments. In addition to framing the disorder as a form of "mind-body overload" which is an approach used in our clinic, other helpful and widely used approaches include the software vs. hardware analogy developed astutely by Stone and Carson. ${ }^{19,20}$ Lastly, for patients that have received a different diagnosis for their motor symptoms, we encourage relying on the rule-in physical examination signs and semiological features to provide a non-judgmental opinion regarding the provider's rationale for why the patient's symptom complex is consistent with the mFND phenotype. Encouraging the patient to learn more about the spectrum of mFND through information available on www.neurosymptoms. org can also be a useful aid in these challenging discussions.

Once the diagnosis has been discussed (taking about 5-7 minutes), it is important to not continue to "talk at the patient", pausing to allow the patient to ask questions. For patients who may look skeptical but are not asking questions, it can be helpful to encourage them to express any concerns that they may have about the opinion provided. It is at this juncture where the physician can reflect on the patient's level of diagnostic acceptance and readiness to discuss treatments. If the patient is expressing significant doubts, the recommendation may be for the patient to explore printed and online materials and to return in follow-up to continue the discussion and explore possible treatment options at a later date. For a small minority of patients, despite multiple follow-up visits and provider discussions, some patients may continue to reject the diagnosis of mFND or request a continued (or repeat) medical/ neurological evaluation despite adequate workup and discussion of the diagnosis. In those limited cases, providers can be encouraged to express nonjudgmentally the rationale for their diagnostic impressions (based on rule-in signs), while also noting the patient is free to agree or disagree. Such individuals can be offered a second opinion (preferably with a clinician who has broad neurological expertise including being up-to-date in the diagnostic approach to mFND), with comments that the patient is 
welcomed back in the future if they would like to revisit mFND specific care. Despite the above important qualifiers, many patients are receptive to the diagnosis, with the conversation subsequently transitioning to discussing treatment options.

There is growing evidence for two primary treatments: motor retraining through physiotherapy (for FND-movt and FND-par) and skills-based psychotherapy (generally performed by a psychiatrist, psychologist or social workerpsychotherapist), particularly CBT. ${ }^{15-18}$ Based on individual patient needs, we generally recommend CBT for most patients that are interested in such treatment and motor retraining based on the specifics of the symptom complex. Below are descriptions of motor retraining and psychotherapy that will aid the development of shared expertise across providers from different backgrounds. This is important because the coordinating physician (typically the neurologist or neuropsychiatrist making the diagnosis) needs to be able to answer questions such as "How will psychotherapy help me walk better?" or questions regarding a physiotherapy referral when they have "already done physiotherapy and it did not help." While beyond the scope of this article, occupational therapy and speech and language therapy are also emerging first-line treatments discussed elsewhere. ${ }^{80-83}$

\section{Physiotherapy}

A 2013 systematic review identified 29 studies performed between 1970 and 2013 that looked at physiotherapy for mFND and overall found a $>50 \%$ success rates. ${ }^{84}$ Since then, there have been additional studies supporting a role for specialized physiotherapy, ${ }^{85}$ and consensus recommendations by Nielsen et al guiding physiotherapy treatment were published in 2015 (including a long version with guidance on specific physiotherapy interventions for the various FND-par and FND-movt phenotypes). ${ }^{15}$ There is currently a large multicenter randomized controlled trial underway in the United Kingdom. ${ }^{86}$

Physiotherapy for mFND focuses on education, demonstration that normal movement can occur, changing unhelpful behaviors, and retraining normal movements through diverted attention. ${ }^{7}$ Understanding the mechanisms behind mFND helps guide rehabilitation, and physical therapists should be aware that functional motor symptoms often worsen when attention is directed toward them and improve with distraction. ${ }^{87}$ This provides the rationale for setting up physiotherapy to maximize the role of distractors or other strategies that direct attention away from symptoms and towards goal-oriented tasks. ${ }^{24}$ Goal setting should be done collaboratively between patient and therapist from the beginning to set realistic expectations and involve the patient as an active participant in the care plan. In addition, the biopsychosocial formulation can help to identify reasons why a patient may not be making progress in treatment. ${ }^{15}$

\section{Core Physiotherapy Elements}

\section{Education}

Education should be utilized throughout treatment. Early on this includes discussing the patient's diagnosis with them and ensuring good understanding. ${ }^{15}$ Education also includes explaining that physiotherapy is working to maximize times of typical movement patterns in order to minimize the learned behaviors of their atypical movements.

\section{Role of Attention}

Rather than emphasizing isolated motor exercises (i.e., activating muscles in lower extremity during sit to stand), physiotherapy for mFND should emphasize the task as a whole while utilizing a distraction. For example, a sit to stand while tossing a ball to the therapist brings attention away from the affected $\operatorname{limb}(\mathrm{s})$ and towards the dual task of tossing the ball. On a simpler level, this may include having the patient shift focus to a non-involved limb or asking them to use a cognitive challenge such as counting backwards by 3's. Some patients find a sensory distractor helpful, such as placing a stimulating object in their hand during gait practice. Patients should actively participate in selecting optimal strategies and the role for distraction should be explained.

\section{Home Exercise}

Practice of techniques learned during physiotherapy sessions are essential for patients with mFND, however, it is often a challenge to create a home exercise program when the focus is away from impairment-based treatment. We have found that emphasizing daily practice of strategies to maximize time spent performing more typical motor behaviors are a helpful home task. Movement retraining is described as a balancing act, with every period of practice adding to the side aiding typical movement attempts to override atypical patterns. Additionally, patients are encouraged to increase participation in the activities that do not worsen symptoms and to gradually expand their range of activities. 


\section{Triaging Challenges}

Beliefs that movements will worsen symptoms or prove painful / dangerous can be perpetuating factors. ${ }^{15}$ These beliefs and accompanying avoidance behaviors contribute to an anticipatory anxiety that can often amplify symptoms and impede recovery. This can be addressed through various methods including education and challenging thoughts through exposure to movement in a safe and effective way. Often, performing the movement with supervision and/or using distraction can result in different movement patterns without negative consequences. As individuals repeatedly perform the movement successfully with support from a therapist, they will challenge their own negative thoughts. This can also be applied to fear of falling that often impacts patients with a functional gait disorder. Principles of graded exposure apply here so that the patient is safely able to challenge expectations about movement. ${ }^{88}$ Other common themes include the idea of "boom or bust" activity that involves patients doing a large amount of activity when feeling relatively good and subsequently crashing with increased symptoms for several days at a time.$^{89}$ Pointing this out to the patient (often in collaboration with their psychotherapist) is essential. Here, the goal can be to guide the patient in understanding that often less is more and always pushing through symptoms does not necessarily equal greater gains. These themes highlight the close relationship between physical and psychological treatments.

The presence of pain, fatigue, FND-seiz and other symptoms can also present challenges in physiotherapy. These symptoms should be addressed early to determine appropriate next steps. With all of these additional symptoms, treatment with another discipline may need to be prioritized prior to initiating physiotherapy. For example, the patient with chronic pain whose primary complaint is pain may benefit first from a multidisciplinary pain program. ${ }^{90}$ Similarly, those with substantial non-motor bodily symptoms and/or comorbid FND-seiz may benefit from initiating psychotherapy first. This tiered approach may optimize engagement as the patient is not overwhelmed by numerous parallel therapies. For those with pain/fatigue in physiotherapy, treatment will also need to be ramped up slowly and include pain science education. Comorbid FND-seiz pose challenges as they can interrupt sessions, and it can be helpful for physical therapists to have some familiarity with FND-seiz and a plan for how to address events if they occur during treatment sessions. If the balance between seizure activity and other functional movement difficulties is heavily tipped towards FND-seiz, that may warrant postponing physiotherapy temporarily. Many with FND-seiz can participate fully in physiotherapy as they become more aware of warning signs and are able to prevent events or work with staff to safely manage events.

\section{Treatment Setting}

Various treatment models and settings have been studied, however, the optimal frequency and intensity for physiotherapy in mFND has not yet been identified. ${ }^{24}$ At our center, we encourage patients to come in for one hour of weekly outpatient physiotherapy treatment, establishing the expectation that the desired minimum frequency is at least every other week. ${ }^{24}$ Some patients with severe motor symptoms may require inpatient or more intensive outpatient treatments that are currently being investigated. ${ }^{91}$

\section{Psychotherapy}

CBT is a widely studied psychotherapy for mFND. ${ }^{16-18,92-96}$ It should be noted upfront, however, that considerable more work is needed to optimize and individualize psychotherapy approaches in mFND. ${ }^{93,97}$ The components of this timelimited, structured treatment address psychological factors perpetuating FND symptoms. Elements of the approach include three main areas - thoughts, emotions and behavior - that dynamically interact within a patient's social context and illness model. CBT interventions target unhelpful traits that perpetuate symptoms in patients diagnosed with mFND through the development of new skills. Available CBT treatment manuals for FND include two evidence-based workbooks, Overcoming Functional Neurological Disorder: a 5 Areas Approach (a self-guided manual that we use as a guide for individual psychotherapy) ${ }^{89}$ and Taking Control of Your Seizures, a workbook for treating FND-seiz. ${ }^{98}$ Both manuals provide patients with an enhanced "toolbox" of skills for symptom management. In the near future, the CBT manual based on Goldstein's fear-avoidance treatment model for FND-seiz is also expected to become available. ${ }^{93}$

Patients with FND may demonstrate unhelpful cognitions, health anxiety and/or fixed illness beliefs that can perpetuate symptoms and contribute to reduced stress coping. ${ }^{99}$ Cognitive restructuring helps identify and challenge inaccurate core beliefs, negative automatic thoughts and the resulting emotional states that drive symptoms. A core component of cognitive restructuring is the use of the Socratic method, ${ }^{100}$ which challenges the tendency to 
experience events negatively while supporting the patient to identify alternative perspectives. This is achieved in a stepped fashion beginning with the identification of problematic categories of thinking (termed cognitive distortions), including tendencies to catastrophize, view events through a negative filter, or make extreme statements or rules. Patients learn to question the validity of negative automatic thoughts and emotions stemming from these appraisals. Finally, more adaptive perspectives and strategies are generated to address problems.

Patients with $\mathrm{mFND}$ can display tendencies towards behavioral and emotional avoidance. ${ }^{26}$ This can manifest as a progressive reduction of activity, greater dependency on others, avoidance of certain emotional states, and/or social isolation. Patients may also engage in boom-andbust patterns of activity or exhibit perfectionistic (and obsessional) approaches to task completion that can be self-defeating. ${ }^{89}$ Addressing behavioral and emotional avoidance and other perpetuating patterns through improved recognition, while increasing self-efficacy are points of treatment focus. Primary behavioral therapeutic strategies include use of graded exposure and instruction in distraction and refocusing techniques. Improving awareness of the mind-body connection assists patients in learning to observe and then modulate their bodily stress responses. The use of relaxation techniques to regulate negative emotions and related arousal (fight or flight) symptoms is an important component of psychotherapy for mFND that helps patients detect bodily warning signs of impending functional neurological episodes. Improved awareness can be coupled with relaxation exercises (e.g., diaphragmatic breathing, progressive muscle relaxation) to induce the relaxation response. ${ }^{101}$

We still do not fully understand the role that CBT plays in the treatment of $\mathrm{mFND}$, as highlighted by the recent publication (2020) of the largest randomized controlled trial of CBT for the treatment of FND-seiz. ${ }^{93} 368$ patients recruited from outpatient neurology clinics were randomized to CBT plus standardized medical care vs standardized medical care alone. Although no significant difference in 4-week seizure frequency (primary outcome) was observed between treatment arms at 12-months, several secondary outcomes favored CBT treatment (including longer period of seizure freedom during the last 6 months of the study and improved psychosocial functioning and health-related quality of life). The lack of a statistically significant difference in the primary outcome suggests that more work is needed to fully understand the role of CBT in the management of $\mathrm{mFND}$, including investigating if it may prove more efficacious to use clinical formulations to guide psychotherapy treatment modality selection. ${ }^{97}$

In our experience, the biopsychosocial formulation can be helpful in pairing appropriate psychotherapeutic interventions to patients given the considerable heterogeneity within patients. For example, some with mFND will have had prior extensive experience with mental health care, while others may not have previously seen a mental health provider. Additionally, we have found that the vast majority of patients are appropriate for an initial skills-based CBT approach, however, during treatment it may become clear that other psychotherapeutic tools outside the prescribed manuals may allow the treatment to be more beneficial. The CODES trial therapists themselves cited the importance of the clinical formulation in orienting the treatment for an individual patient. ${ }^{102}$

Within the therapeutic setting it may become apparent that an alternative treatment based on clinical formulation (e.g., ongoing trauma-related symptoms and good insight into the connection between mFND and PTSD) may be warranted (See Table 3). Prolonged exposure therapy (PE), a type of cognitive behavioral therapy first developed as a treatment for PTSD, is designed to address avoidance strategies that arise as defensive reactions around traumarelated symptoms. The approach utilizes imagined and invivo exposure to trauma material. ${ }^{103}$ A 2016 study of $\mathrm{PE}$ in patients with FND-seiz and PTSD by Myers et al reported cessation of seizures in 13 of 16 patients studied and a decline in seizure frequency in the other 3 patients by end of treatment. ${ }^{104}$ Others may benefit from mindfulness-based interventions, with a primary goal of developing non-judgmental awareness of present moment experience through acceptance. ${ }^{105}$ In a recent study of a 12-session mindfulness-based therapy developed for FND-seiz ( $\mathrm{n}=26), 70 \%$ endorsed reduction of seizures by at least $50 \%$ by the conclusion of treatment. ${ }^{106}$ Dialectical behavior therapy (DBT) is an evidence-based psychotherapy that has been shown to be an effective intervention for affect dysregulation that also incorporate elements of mindfulness training. ${ }^{107}$ DBT is a manualized treatment consisting of 4 modules: core mindfulness, distress tolerance, emotion regulation, and interpersonal effectiveness. In a 2015 pilot study, 17 patients diagnosed with FND-seiz completed 20.5 weeks of group DBT treatment. ${ }^{108}$ Mean seizure frequency decreased by $66 \%$ and cessation of seizures were experienced by $35 \%$ of the cohort by the end of treatment. Other psychotherapies have been studied 
Table 3 Brief Description of the Psychotherapy Treatment Modalities with Emerging Evidence in Motor Functional Neurological Disorders (mFND)

\begin{tabular}{|c|c|c|}
\hline Psychotherapy & Core Components & $\begin{array}{l}\text { Examples of } \\
\text { Supporting } \\
\text { Evidence }\end{array}$ \\
\hline $\begin{array}{l}\text { Cognitive Behavioral } \\
\text { Therapy (CBT) }\end{array}$ & $\begin{array}{l}\mathrm{CBT} \text { interventions focus on the interaction between thoughts, emotions and behaviors } \\
\text { and how these perpetuate functional neurological symptoms. Components include } \\
\text { education, cognitive restructuring, use of graded exposure, distraction techniques, and } \\
\text { relaxation skills training. }\end{array}$ & $\begin{array}{l}\text { Sharpe et al }\left.\right|^{16^{*}} \\
\text { LaFrance et al }{ }^{17^{*}, 94} \\
\text { Goldstein et al }\left.\right|^{92 * 93} \\
\text { O'Connell et al }{ }^{96} \\
\text { Espay et al }{ }^{18}\end{array}$ \\
\hline $\begin{array}{l}\text { Prolonged Exposure } \\
\text { Therapy (PE) }\end{array}$ & $\begin{array}{l}\text { PE utilizes imaginal and in vivo exposure methods to address strategies of avoidance and } \\
\text { hyperarousal that arise as defensive reactions around trauma-related symptoms. }\end{array}$ & Myers et $\mathrm{al}^{104}$ \\
\hline $\begin{array}{l}\text { Dialectical Behavior } \\
\text { Therapy (DBT) }\end{array}$ & $\begin{array}{l}\text { DBT is a manualized psychotherapy developed to treat affective dysregulation in a range of } \\
\text { psychiatric conditions. Treatment consists of } 4 \text { modules: core mindfulness, distress } \\
\text { tolerance, emotion regulation, and interpersonal effectiveness. }\end{array}$ & Bullock et at ${ }^{108}$ \\
\hline $\begin{array}{l}\text { Mindfulness-Based Therapy } \\
\text { (MBT) }\end{array}$ & $\begin{array}{l}\text { MBT centers around the use of mindfulness techniques with a primary goal of developing } \\
\text { present moment awareness with acceptance. }\end{array}$ & Baslet et al ${ }^{106}$ \\
\hline $\begin{array}{l}\text { Acceptance and } \\
\text { Commitment Therapy } \\
\text { (ACT) }\end{array}$ & $\begin{array}{l}\text { ACT is a therapeutic intervention aimed at increasing psychological flexibility through the } \\
\text { use of acceptance and mindfulness strategies. }\end{array}$ & Barrett-Naylor et al ${ }^{\prime \prime \prime}$ \\
\hline $\begin{array}{l}\text { Psychodynamic } \\
\text { Interpersonal Therapy } \\
\text { (PIT) }\end{array}$ & $\begin{array}{l}\text { A structured brief treatment based on psychodynamic principles, PIT treatments utilize } \\
\text { the patient-therapist relationship as the change-agent, allowing for an exploration of } \\
\text { unconscious internal processes through a focus on emotions in the present moment. }\end{array}$ & Kompoliti et al ${ }^{110}$ \\
\hline
\end{tabular}

Notes: *Indicates randomized CBT clinical trials that showed efficacy for the treatment of mFND based on primary outcome measures. More research is needed to optimize psychotherapy treatments in $\mathrm{mFND}$, including investigating the extent to which clinical formulations aid the pairing of patients to specific psychotherapy treatment modalities.

including psychodynamic psychotherapy, acceptance and commitment psychotherapy and group psychotherapy that are discussed elsewhere. ${ }^{109-111}$

\section{Longitudinal Management}

Issues not yet addressed here include the management of psychiatric comorbidities, team structure, longitudinal follow-up, and collaborative approaches between community-based clinicians and hospital-based FND clinical programs. For many patients, we have found that it is advisable to begin with education and ensure that there is initial patient engagement in physiotherapy and CBT prior to exploring potential use of psychotropic medications for symptom management regarding affective symptoms. The rationale for this is three-fold: 1) leading with a medication may help perpetuate an external locus of control (the physician and the pill are the primary treatments), rather than encouraging the patient to consider their own equally important role in recovery; 2) some patients with mFND may be somatically hypervigilant, as exemplified by associations between medication tolerances and illness duration. ${ }^{6}$ Thus, when psychotropic medications are introduced, it can be helpful to do so at low doses and note that an early "flair up" of functional neurological symptoms with medication initiation does not necessarily imply that the medication will not prove helpful in the intermediate term. 3) Psychotropic medications are not directly treating $\mathrm{mFND}$, but rather are addressing affective disturbances that may be perpetuating functional neurological symptoms. Additionally, there can be roles for tapering medications that may not be indicated, such as anti-epileptic drugs in patients with isolated FND-seiz or high doses of pain medications with secondary side effects. It is helpful to engage patients as partners in these decisions, while also being clear about an inability to increase medications that are not indicated.

With regards to team structure and longitudinal followup, our general principle is shared (partially overlapping) expertise across neurology, psychiatry, allied mental health disciplines and rehabilitation specialties. In our opinion there is no "one perfect team structure", but it is clear that neurological expertise and psychiatric/psychological expertise are core skills that are needed in the physician lead, which alternatively can be accomplished by having several members across the clinical neurosciences work together to colead the clinical assessment and longitudinal management of 
mFND. In our opinion, the physician "team" lead should generally be a psychologically-minded neurologist or a psychiatrist with additional neurological training (generally a neuropsychiatrist). We would like to highlight that while the neurologist or neuropsychiatrist member of the team may not be performing psychotherapy, follow-up visits are primed to catalyze psychological insights by helping the patient make connections between neurological symptoms, thoughts, behaviors, emotions and life factors. ${ }^{27,28}$ When such connections are uncovered, this can also be a nice segue into asking the patient to follow-up with their psychotherapist on these themes. To be clear, apart from referrals to physiotherapy for motor retraining and a psychotherapist for CBT, a physician lead must remain actively involved in longitudinal care and collaborating with other members of the treatment team to ensure consistent and coordinated care.

Collaborations between specialty mFND treatment programs and community-based clinics are also important points to discuss. ${ }^{30}$ For the foreseeable future, there are and will likely continue to be far too few specialized treatment programs for all patients with mFND to receive care within the bandwidth of such programs. ${ }^{29}$ One approach is to empower community neurologists to accurately diagnosis FND based on rule-in signs, provide education using websites such as www.neurosymp toms.org and rely on the consensus recommendations for physiotherapy (and occupational therapy) to guide community-based rehabilitation (the recommendations can be printed out in the clinic with instructions for the patient to provide these to their assigned physical therapist). ${ }^{15,83}$ Recommending the self-guided CBT workbook Overcoming Functional Neurological Disorder: a 5 Areas Approach could complement motor retraining, ${ }^{16}$ and community-based psychiatric consultation could be sought for those endorsing prominent affective symptoms. For this approach to prove feasible, educational efforts to increase awareness and training in the assessment and management of mFND need to be exponentially increased across the clinical neurosciences and rehabilitation specialties. For patients that are more neuropsychiatrically complex or those that do not respond to initial treatments, such individuals could then be referred onto a specialized program. Additionally, hybrid models are likely a good option as well (and frequently employed in our clinical program). In such cases, individuals can continue to receive care from community neurologists and mental health providers (aimed at primarily addressing the neurologic and psychiatric comorbidities that are prevalent in this population), while clinicians in the specialty mFND program focus primarily on the assessment and management of functional motor symptoms. In this latter approach, good communication across treatment providers is important - which can be achieved by having providers send notes to one another, leveraging integrated electronic medical record systems and intermittent telephone (or video conference) calls.

\section{Conclusions}

In summary, this article details an approach to the outpatient assessment and management of mFND based on emerging evidence and our own experience initiating and growing an interdisciplinary program for patients with functional motor symptoms. More research is needed to optimize the clinical approach and treatment pathways for mFND. Our hope is that this perspective article will help encourage increased enthusiasm by providers across the clinical neurosciences and rehabilitation specialties to rise to the challenge in caring for this prevalent and underserved neuropsychiatric disorder.

\section{Funding}

D.L.P. and J.M. were funded by the Sidney R. Baer Jr. Foundation. D.L.P. also received funding from the Massachusetts General Hospital Physician-Scientist Career Development Award.

\section{Disclosure}

D.L.P has received honoraria for continuing medical lectures in functional neurological disorder from Harvard Medical School. The authors report no other conflicts of interest in this work.

\section{References}

1. Stone J, Carson A, Duncan R, et al. Who is referred to neurology clinics?-The diagnoses made in 3781 new patients. Clin Neurol Neurosurg. 2010;112(9):747-751. doi:10.1016/j.clineuro.2010. 05.011

2. Perez DL, Aybek S, Nicholson TR, Kozlowska K, Arciniegas DB, LaFrance WC Jr. Functional neurological (conversion) disorder: a core neuropsychiatric disorder. $J$ Neuropsychiatry Clin Neurosci. 2020;32(1):1-3. doi:10.1176/appi.neuropsych.19090204

3. Espay AJ, Aybek S, Carson A, et al. Current concepts in diagnosis and treatment of functional neurological disorders. JAMA Neurol. 2018;75(9):1132-1141. doi:10.1001/jamaneurol.2018.1264

4. Pick S, Goldstein LH, Perez DL, Nicholson TR. Emotional processing in functional neurological disorder: a review, biopsychosocial model and research agenda. $J$ Neurol Neurosurg Psychiatry. 2019;90(6):704-711. doi:10.1136/jnnp-2018-319201 
5. McKenzie PS, Oto M, Graham CD, Duncan R. Do patients whose psychogenic non-epileptic seizures resolve, 'replace' them with other medically unexplained symptoms? Medically unexplained symptoms arising after a diagnosis of psychogenic non-epileptic seizures. J Neurol Neurosurg Psychiatry. 2011;82(9):967-969. doi:10.1136/jnnp.2010.231886

6. Matin N, Young SS, Williams B, et al. Neuropsychiatric associations with gender, illness duration, work disability and motor subtype in a US functional neurological disorders clinic population. $J$ Neuropsychiatry Clin Neurosci. 2017;29 (4):375-382. doi:10.1176/appi.neuropsych.16110302

7. Gelauff JM, Kingma EM, Kalkman JS, et al. Fatigue, not self-rated motor symptom severity, affects quality of life in functional motor disorders. $J$ Neurol. 2018;265(8):1803-1809. doi:10.1007/s00415-018-8915-7

8. Stone J, Warlow C, Sharpe M. The symptom of functional weakness: a controlled study of 107 patients. Brain. 2010;133(Pt 5):1537-1551. doi:10.1093/brain/awq068

9. Gelauff JM, Carson A, Ludwig L, Tijssen MAJ, Stone J. The prognosis of functional limb weakness: a 14-year case-control study. Brain. 2019;142(7):2137-2148. doi:10.1093/brain/awz138

10. Alluri PR, Solit J, Leveroni CL, et al. Cognitive complaints in motor functional neurological (conversion) disorders: a focused review and clinical perspective. Cogn Behav Neurol. 2020;33 (2):77-89. doi:10.1097/WNN.0000000000000218

11. LaFrance WC Jr, Baker GA, Duncan R, Goldstein LH, Reuber M. Minimum requirements for the diagnosis of psychogenic nonepileptic seizures: a staged approach: a report from the international league against epilepsy nonepileptic seizures task force. Epilepsia. 2013;54(11):2005-2018. doi:10.1111/epi.12356

12. Baslet G, Bajestan SN, Aybek S, et al. Evidence-based practice for the clinical assessment of psychogenic nonepileptic seizures: a report from the American Neuropsychiatric Association committee on research. J Neuropsychiatry Clin Neurosci. 2020:appineuropsych19120354. doi:10.1176/appi neuropsych.19120354

13. Schwingenschuh P, Katschnig P, Seiler S, et al. Moving toward "laboratory-supported" criteria for psychogenic tremor. Mov Disord. 2011;26(14):2509-2515. doi:10.1002/mds.23922

14. Perez DL, Aybek S, Popkirov S, et al. A review and expert opinion on the neuropsychiatric assessment of motor functional neurological disorders. J Neuropsychiatry Clin Neurosci. 2020:appineuropsych19120357. doi:10.1176/appi.neuropsych.19120357

15. Nielsen G, Stone J, Matthews A, et al. Physiotherapy for functional motor disorders: a consensus recommendation. $J$ Neurol Neurosurg Psychiatry. 2015;86(10):1113-1119. doi:10.1136/jnnp2014-309255

16. Sharpe M, Walker J, Williams C, et al. Guided self-help for functional (psychogenic) symptoms: a randomized controlled efficacy trial. Neurology. 2011;77(6):564-572. doi:10.1212/ WNL.0b013e318228c0c7

17. LaFrance WC Jr, Baird GL, Barry JJ, et al. Multicenter pilot treatment trial for psychogenic nonepileptic seizures: a randomized clinical trial. JAMA Psychiat. 2014;71(9):997-1005. doi:10.1001/ jamapsychiatry.2014.817

18. Espay AJ, Ries S, Maloney T, et al. Clinical and neural responses to cognitive behavioral therapy for functional tremor. Neurology. 2019;93(19):e1787-e1798. doi:10.1212/WNL.0000000000008442

19. Stone J, Carson A. Functional neurologic disorders. Continuum (Minneap Minn). 2015;21(3Behavioral Neurology and Neuropsychiatry):818-837. doi:10.1212/01.CON.0000466669.024 77.45

20. Stone J, Carson A. Functional neurologic symptoms: assessment and management. Neurol Clin. 2011;29(1):1-18, vii. doi:10.1016/ j.ncl.2010.10.011
21. McKee K, Glass S, Adams C, et al. The inpatient assessment and management of motor functional neurological disorders: an interdisciplinary perspective. Psychosomatics. 2018;59(4):358-368. doi:10.1016/j.psym.2017.12.006

22. Anderson JR, Nakhate V, Stephen CD, Perez DL. Functional (psychogenic) neurological disorders: assessment and acute management in the emergency department. Semin Neurol. 2019;39 (1):102-114. doi:10.1055/s-0038-1676844

23. Glass SP, Matin N, Williams B, et al. Neuropsychiatric factors linked to adherence and short-term outcome in a U.S. functional neurological disorders clinic: a Retrospective Cohort Study. $J \quad$ Neuropsychiatry Clin Neurosci. 2018;30(2):152-159. doi:10.1176/appi.neuropsych.17060117

24. Maggio JB, Ospina JP, Callahan J, Hunt AL, Stephen CD, Perez DL. Outpatient physical therapy for functional neurological disorder: a preliminary feasibility and Naturalistic Outcome Study in a U.S. cohort. J Neuropsychiatry Clin Neurosci. 2020;32 (1):85-89. doi:10.1176/appi.neuropsych.19030068

25. Jalilianhasanpour R, Ospina JP, Williams B, et al. Secure attachment and depression predict 6-month outcome in motor functional neurological disorders: a Prospective Pilot Study. Psychosomatics. 2018. doi:10.1016/j.psym.2018.08.004

26. Perez DL, Young SS, King JN, et al. Preliminary predictors of initial attendance, symptom burden, and motor subtype in a US functional neurological disorders clinic population. Cogn Behav Neurol. 2016;29(4):197-205. doi:10.1097/WNN.0000000000000106

27. Reuber M. Dissociative (non-epileptic) seizures: tackling common challenges after the diagnosis. Pract Neurol. 2019;19 (4):332-341. doi:10.1136/practneurol-2018-002177

28. Adams C, Anderson J, Madva EN, LaFrance WC Jr, Perez DL. You've made the diagnosis of functional neurological disorder: now what? Pract Neurol. 2018;18(4):323-330. doi:10.1136/practneurol-2017-001835

29. Aybek S, Lidstone SC, Nielsen G, et al. What is the role of a specialist assessment clinic for FND? Lessons from three national referral centers. $J$ Neuropsychiatry Clin Neurosci. 2020;32(1):79-84. doi:10.1176/appi.neuropsych.19040083

30. Perez DL, Haller AL, Espay AJ. Should neurologists diagnose and manage functional neurologic disorders? It is complicated. Neurol Clin Pract. 2019;9(2):165-167. doi:10.1212/CPJ.0000 000000000573

31. Perez DL, Keshavan MS, Scharf JM, Boes AD, Price BH. Bridging the great divide: what can neurology learn from psychiatry? J Neuropsychiatry Clin Neurosci. 2018;30 (4):271-278. doi:10.1176/appi.neuropsych.17100200

32. Goldstein LH, Mellers JD. Ictal symptoms of anxiety, avoidance behaviour, and dissociation in patients with dissociative seizures. $J$ Neurol Neurosurg Psychiatry. 2006;77(5):616-621. doi:10.1136/jnnp.2005.066878

33. Parees I, Kojovic M, Pires C, et al. Physical precipitating factors in functional movement disorders. J Neurol Sci. 2014;338(1-2):174-177. doi:10.1016/j.jns.2013.12.046

34. Stone J, Carson A, Aditya H, et al. The role of physical injury in motor and sensory conversion symptoms: a systematic and narrative review. J Psychosom Res. 2009;66(5):383-390. doi:10.1016/ j.jpsychores.2008.07.010

35. Ranford J, MacLean J, Alluri PR, et al. Sensory processing difficulties in functional neurological disorder: a possible predisposing vulnerability? Psychosomatics. 2020;61(4):343-352. doi:10.1016/j.psym.2020.02.003

36. Nicholson TR, Carson A, Edwards MJ, et al. Outcome measures for functional neurological disorder: a review of the theoretical complexities. J Neuropsychiatry Clin Neurosci. 2020;32 (1):33-42. doi:10.1176/appi.neuropsych.19060128

37. McWhirter L, Ritchie C, Stone J. Functional cognitive disorders: a systematic review. Lancet Psychiat. 2020;7(2):191-207. 
38. Kutlubaev MA, Xu Y, Hackett ML, Stone J. Dual diagnosis of epilepsy and psychogenic nonepileptic seizures: systematic review and meta-analysis of frequency, correlates, and outcomes. Epilepsy Behav. 2018;89:70-78. doi:10.1016/j. yebeh.2018.10.010

39. Wissel BD, Dwivedi AK, Merola A, et al. Functional neurological disorders in parkinson disease. $J$ Neurol Neurosurg Psychiatry. 2018;89(6):566-571. doi:10.1136/jnnp-2017-317378

40. Sharpe M, Stone J, Hibberd C, et al. Neurology out-patients with symptoms unexplained by disease: illness beliefs and financial benefits predict 1-year outcome. Psychol Med. 2010;40 (4):689-698. doi:10.1017/S0033291709990717

41. Rao SR, Slater JD, Kalamangalam GP. A simple clinical score for prediction of nonepileptic seizures. Epilepsy Behav. 2017;77:50-52. doi:10.1016/j.yebeh.2017.09.005

42. Carson A, Lehn A, Ludwig L, Stone J. Explaining functional disorders in the neurology clinic: a photo story. Pract Neurol. 2016;16(1):56-61. doi:10.1136/practneurol-2015-001242

43. Kranick S, Ekanayake V, Martinez V, Ameli R, Hallett M, Voon V. Psychopathology and psychogenic movement disorders. Mov Disord. 2011;26(10):1844-1850. doi:10.1002/ mds. 23830

44. Gray C, Calderbank A, Adewusi J, Hughes R, Reuber M. Symptoms of posttraumatic stress disorder in patients with functional neurological symptom disorder. $J$ Psychosom Res. 2020;129:109907. doi:10.1016/j.jpsychores.2019.109907

45. Goldstein LH, Robinson EJ, Mellers JDC, et al. Psychological and demographic characteristics of 368 patients with dissociative seizures: data from the CODES cohort. Psychol Med. 2020:1-13. doi:10.1017/S0033291720001051

46. Scarella TM, Boland RJ, Barsky AJ. Illness anxiety disorder: psychopathology, epidemiology, clinical characteristics, and treatment. Psychosom Med. 2019;81(5):398-407. doi:10.1097/ PSY.0000000000000691

47. Ludwig L, Pasman JA, Nicholson T, et al. Stressful life events and maltreatment in conversion (functional neurological) disorder: systematic review and meta-analysis of case-control studies. Lancet Psychiat. 2018;5(4):307-320. doi:10.1016/S2215-0366(18)30051-8

48. Stone J, Hoeritzauer I, Gelauff J, et al. Functional disorders in neurology: case studies. Neurol Clin. 2016;34(3):667-681. doi:10.1016/j.ncl.2016.04.013

49. Lyssenko L, Schmahl C, Bockhacker L, Vonderlin R, Bohus M, Kleindienst N. Dissociation in psychiatric disorders: a meta-analysis of studies using the dissociative experiences scale. Am J Psychiatry. 2018;175(1):37-46. doi:10.1176/appi. ajp.2017.17010025

50. Demartini B, Petrochilos P, Ricciardi L, Price G, Edwards MJ, Joyce E. The role of alexithymia in the development of functional motor symptoms (conversion disorder). J Neurol Neurosurg Psychiatry. $\quad 2014 ; 85(10): 1132-1137 . \quad$ doi:10.1136/jnnp-2013307203

51. Ludwig L, Whitehead K, Sharpe M, Reuber M, Stone J. Differences in illness perceptions between patients with non-epileptic seizures and functional limb weakness. J Psychosom Res. 2015;79(3):246-249. doi:10.1016/j. jpsychores.2015.05.010

52. Reuber M, Howlett S, Khan A, Grunewald RA. Non-epileptic seizures and other functional neurological symptoms: predisposing, precipitating, and perpetuating factors. Psychosomatics. 2007;48(3):230-238. doi:10.1176/appi.psy.48.3.230

53. Moitra E, Duarte-Velez Y, Lewis-Fernandez R, Weisberg RB, Keller MB. Examination of ataque de nervios and ataque de nervios like events in a diverse sample of adults with anxiety disorders. Depress Anxiety. 2018;35(12):1190-1197. doi:10.1002/ da. 22853
54. Ospina JP, Larson AG, Jalilianhasanpour R, et al. Individual differences in social network size linked to nucleus accumbens and hippocampal volumes in functional neurological disorder: a pilot study. J Affect Disord. 2019;258:50-54. doi:10.1016/j. jad.2019.07.061

55. Vaidya-Mathur U, Myers L, Laban-Grant $\mathrm{O}$, Lancman $\mathrm{M}$, Lancman M, Jones J. Socialization characteristics in patients with psychogenic nonepileptic seizures (PNES). Epilepsy Behav. 2016;56:59-65. doi:10.1016/j.yebeh.2015.12.032

56. Espay AJ, Lang AE. Phenotype-specific diagnosis of functional (psychogenic) movement disorders. Curr Neurol Neurosci Rep. 2015;15(6):32. doi:10.1007/s11910-015-0556-y

57. Barbey A, Aybek S. Functional movement disorders. Curr Opin Neurol. 2017;30(4):427-434. doi:10.1097/WCO.000000000 0000464

58. Daum C, Hubschmid M, Aybek S. The value of 'positive' clinical signs for weakness, sensory and gait disorders in conversion disorder: a systematic and narrative review. $J$ Neurol Neurosurg Psychiatry. 2014;85(2):180-190. doi:10.1136/jnnp-2012-304607

59. Avbersek A, Sisodiya S. Does the primary literature provide support for clinical signs used to distinguish psychogenic nonepileptic seizures from epileptic seizures? J Neurol Neurosurg Psychiatry. 2010;81(7):719-725. doi:10.1136/jnnp.2009.197996

60. Nonnekes J, Ruzicka E, Serranova T, Reich SG, Bloem BR, Hallett M. Functional gait disorders: a sign-based approach. Neurology. 2020;94(24):1093-1099. doi:10.1212/WNL.00000000 00009649

61. Ganos C, Martino D, Espay AJ, Lang AE, Bhatia KP, Edwards MJ. Tics and functional tic-like movements: can we tell them apart? Neurology. 2019;93(17):750-758. doi:10.1212/ WNL.0000000000008372

62. Kaski D, Bronstein AM, Edwards MJ, Stone J. Cranial functional (psychogenic) movement disorders. Lancet Neurol. 2015;14 (12):1196-1205. doi:10.1016/S1474-4422(15)00226-4

63. Okun MS, Rodriguez RL, Foote KD, Fernandez HH. The "chair test" to aid in the diagnosis of psychogenic gait disorders. Neurologist. 2007;13(2):87-91. doi:10.1097/01.nrl.0000256358.52613.cc

64. Roper LS, Saifee TA, Parees I, Rickards H, Edwards MJ. How to use the entrainment test in the diagnosis of functional tremor. Pract Neurol. 2013;13(6):396-398. doi:10.1136/practneurol-2013-000549

65. Thenganatt MA, Jankovic J. Psychogenic tremor: a video guide to its distinguishing features. Tremor Other Hyperkinet Mov (N Y). 2014;4:253. doi:10.7916/D8FJ2F0Q

66. Lidstone SC, Lang AE. How do I examine patients with functional tremor? Mov Disord Clin Pract. 2020;7(5):587. doi: $10.1002 / \mathrm{mdc} 3.12966$

67. Stone J, Edwards M. Trick or treat? Showing patients with functional (psychogenic) motor symptoms their physical signs. Neurology. 2012;79(3):282-284. doi:10.1212/WNL.0b013e31825fdf63

68. Perez DL, Hunt A, Sharma N, Flaherty A, Caplan D, Schmahmann JD. Cautionary notes on diagnosing functional neurological disorder as a neurologist-in-training. Neurol Clin Pract. 2019.

69. Perez DL, LaFrance WC Jr. Nonepileptic seizures: an updated review. CNS Spectr. 2016;21(3):239-246. doi:10.1017/ S109285291600002X

70. Asadi-Pooya AA, Bahrami Z. Dramatic presentations in psychogenic nonepileptic seizures. Seizure. 2019;65:144-147. doi:10.1016/j.seizure.2019.01.019

71. Evans RW, Burch RC, Frishberg BM, et al. Neuroimaging for migraine: the American Headache Society Systematic Review and evidence-based guideline. Headache. 2020;60(2):318-336. doi:10.1111/head.13720

72. Baslet G, Dworetzky B, Perez DL, Oser M. Treatment of psychogenic nonepileptic seizures: updated review and findings from a mindfulness-based intervention case series. Clin EEG Neurosci. 2015;46(1):54-64. doi:10.1177/1550059414557025 
73. McKenzie P, Oto M, Russell A, Pelosi A, Duncan R. Early outcomes and predictors in 260 patients with psychogenic nonepileptic attacks. Neurology. 2010;74(1):64-69. doi:10.1212/ WNL.0b013e3181c7da6a

74. Espay AJ, Goldenhar LM, Voon V, Schrag A, Burton N, Lang AE. Opinions and clinical practices related to diagnosing and managing patients with psychogenic movement disorders: an international survey of movement disorder society members. Mov Disord. 2009;24(9):1366-1374. doi:10.1002/mds.22618

75. Hall-Patch L, Brown R, House A, et al. Acceptability and effectiveness of a strategy for the communication of the diagnosis of psychogenic nonepileptic seizures. Epilepsia. 2010;51(1):70-78. doi:10.1111/j.1528-1167.2009.02099.x

76. Kanaan R, Armstrong D, Barnes P, Wessely S. In the psychiatrist's chair: how neurologists understand conversion disorder. Brain. 2009;132(Pt 10):2889-2896. doi:10.1093/brain/awp060

77. Monzoni CM, Duncan R, Grunewald R, Reuber M. How do neurologists discuss functional symptoms with their patients: a conversation analytic study. J Psychosom Res. 2011;71 (6):377-383. doi:10.1016/j.jpsychores.2011.09.007

78. Burke MJ. "It's all in your head"-medicine's silent epidemic. JAMA Neurol. 2019. doi:10.1001/jamaneurol.2019.3043

79. Lidstone SC, Araujo R, Stone J, Bloem BR. Ten myths about functional neurological disorder. Eur J Neurol. 2020. doi:10.1111/ ene. 14310

80. Duffy JR. Functional speech disorders: clinical manifestations, diagnosis, and management. Handb Clin Neurol. 2016;139:379-388. doi:10.1016/B978-0-12-801772-2.00033-3

81. Gardiner P, MacGregor L, Carson A, Stone J. Occupational therapy for functional neurological disorders: a scoping review and agenda for research. CNS Spectr. 2017;1-8. doi:10.1017/S1092852917000797

82. Ranford J, Perez DL, MacLean J. Additional occupational therapy considerations for functional neurological disorders: a potential role for sensory processing. CNS Spectr. 2018;23(3):194-195. doi:10.1017/S1092852918000950

83. Nicholson C, Edwards MJ, Carson AJ, et al. Occupational therapy consensus recommendations for functional neurological disorder. $J$ Neurol Neurosurg Psychiatry. 2020:jnnp-2019-322281. doi:10.1136/jnnp-2019-322281

84. Nielsen G, Stone J, Edwards MJ. Physiotherapy for functional (psychogenic) motor symptoms: a systematic review. J Psychosom Res. 2013;75(2):93-102. doi:10.1016/j.jpsychores.2013.05.006

85. Jordbru AA, Smedstad LM, Klungsoyr O, Martinsen EW. Psychogenic gait disorder: a randomized controlled trial of physical rehabilitation with one-year follow-up. J Rehabil Med. 2014;46(2):181-187. doi:10.2340/16501977-1246

86. Nielsen G, Stone J, Buszewicz M, et al. Physio4FMD: protocol for a multicentre randomised controlled trial of specialist physiotherapy for functional motor disorder. BMC Neurol. 2019;19 (1):242. doi:10.1186/s12883-019-1461-9

87. Baizabal-Carvallo JF, Hallett M, Jankovic J. Pathogenesis and pathophysiology of functional (psychogenic) movement disorders. Neurobiol Dis. 2019;127:32-44. doi:10.1016/j.nbd.2019.02.013

88. Gardiner P, Maggio J, Nielsen G. Chapter 23: Physical Therapy Retraining the Motor System. Springer; 2021.

89. Williams C, Carson A, Smith S, Sharpe M, Cavanagh J, Kent C. Overcoming Functional Neurological Symptoms: A Five Area Approach. CRC Press; 2017.

90. Jimenez XF, Aboussouan A, Johnson J. Functional neurological disorder responds favorably to interdisciplinary rehabilitation models. Psychosomatics. 2019;60(6):556-562. doi:10.1016/j. psym.2019.07.002

91. Jacob AE, Kaelin DL, Roach AR, Ziegler CH, LaFaver K. Motor retraining (MoRe) for functional movement disorders: outcomes from a 1-week multidisciplinary rehabilitation program. PM R. 2018;10(11):1164-1172. doi:10.1016/j.pmrj.2018.05.011
92. Goldstein LH, Chalder T, Chigwedere C, et al. Cognitivebehavioral therapy for psychogenic nonepileptic seizures: a pilot RCT. Neurology. 2010;74(24):1986-1994. doi:10.1212/ WNL.0b013e3181e39658

93. Goldstein LH, Robinson EJ, Mellers JDC, et al. Cognitive behavioural therapy for adults with dissociative seizures (CODES): a pragmatic, multicentre, randomised controlled trial. Lancet Psychiat. 2020;7(6):491-505. doi:10.1016/S2215-0366(20) 30128-0

94. LaFrance WC Jr, Miller IW, Ryan CE, et al. Cognitive behavioral therapy for psychogenic nonepileptic seizures. Epilepsy Behav. 2009;14(4):591-596. doi:10.1016/j.yebeh.2009.02.016

95. Dallocchio C, Tinazzi M, Bombieri F, Arno N, Erro R. Cognitive behavioural therapy and adjunctive physical activity for functional movement disorders (conversion disorder): a pilot, single-blinded, Randomized Study. Psychother Psychosom. 2016;85(6):381-383. doi:10.1159/000446660

96. O’Connell N, Watson G, Grey C, Pastena R, McKeown K, David AS. Outpatient CBT for motor functional neurological disorder and other neuropsychiatric conditions: a retrospective case comparison. J Neuropsychiatry Clin Neurosci. 2020;32 (1):58-66. doi:10.1176/appi.neuropsych.19030067

97. Perez DL. The CODES trial for dissociative seizures: a landmark study and inflection point. Lancet Psychiat. 2020;7(6):464-465. doi:10.1016/S2215-0366(20)30143-7

98. LaFrance WC Jr, Wincze JP. Taking Control of Your Seizures. Workbook. Oxford University Press; 2015.

99. Jalilianhasanpour R, Williams B, Gilman I, et al. Resilience linked to personality dimensions, alexithymia and affective symptoms in motor functional neurological disorders. J Psychosom Res. 2018;107:55-61. doi:10.1016/j. jpsychores.2018.02.005

100. Heiniger LE, Clark GI, Egan SJ. Perceptions of socratic and non-socratic presentation of information in cognitive behaviour therapy. J Behav Ther Exp Psychiatry. 2018;58:106-113. doi:10.1016/j.jbtep.2017.09.004

101. Doll A, Holzel BK, Mulej Bratec S, et al. Mindful attention to breath regulates emotions via increased amygdala-prefrontal cortex connectivity. Neuroimage. 2016;134:305-313. doi:10.1016/j. neuroimage.2016.03.041

102. Wilkinson M, Day E, Purnell J, et al. The experiences of therapists providing cognitive behavioral therapy (CBT) for dissociative seizures in the CODES randomized controlled trial: a qualitative study. Epilepsy Behav. 2020;105:106943. doi:10.1016/j.yebeh.2020.106943

103. Foa EB. Prolonged exposure therapy: past, present, and future. Depress Anxiety. 2011;28(12):1043-1047. doi:10.1002/ da.20907

104. Myers L, Vaidya-Mathur U, Lancman M. Prolonged exposure therapy for the treatment of patients diagnosed with psychogenic non-epileptic seizures (PNES) and post-traumatic stress disorder (PTSD). Epilepsy Behav. 2017;66:86-92. doi:10.1016/j. yebeh.2016.10.019

105. Holzel BK, Lazar SW, Gard T, Schuman-Olivier Z, Vago DR, Ott U. How does mindfulness meditation work? Proposing mechanisms of action from a conceptual and neural perspective. Perspect Psychol Sci. 2011;6(6):537-559. doi:10.1177/ 1745691611419671

106. Baslet G, Ehlert A, Oser M, Dworetzky BA. Mindfulnessbased therapy for psychogenic nonepileptic seizures. Epilepsy Behav. 2020;103(Pt A):106534. doi:10.1016/j.yebeh.2019. 106534

107. Linehan MM, Wilks CR, Course T. Evolution of dialectical behavior therapy. Am J Psychother. 2015;69(2):97-110. doi:10.1176/ appi.psychotherapy.2015.69.2.97 
108. Bullock KD, Mirza N, Forte C, Trockel M. Group dialectical-behavior therapy skills training for conversion disorder with seizures. J Neuropsychiatry Clin Neurosci. 2015;appineuropsych13120359. doi:10.1176/appi.neuropsych.13120359

109. Conwill M, Oakley L, Evans K, Cavanna AE. CBT-based group therapy intervention for nonepileptic attacks and other functional neurological symptoms: a pilot study. Epilepsy Behav. 2014;34:68-72. doi:10.1016/j.yebeh.2014.03.012

110. Kompoliti K, Wilson B, Stebbins G, Bernard B, Hinson V. Immediate vs. delayed treatment of psychogenic movement disorders with short term psychodynamic psychotherapy: randomized clinical trial. Parkinsonism Relat Disord. 2014;20 (1):60-63. doi:10.1016/j.parkreldis.2013.09.018
111. Barrett-Naylor R, Gresswell DM, Dawson DL. The effectiveness and acceptability of a guided self-help Acceptance and Commitment Therapy (ACT) intervention for psychogenic nonepileptic seizures. Epilepsy Behav. 2018;88:332-340. doi:10.1016/ j.yebeh.2018.09.039

\section{Publish your work in this journal}

Neuropsychiatric Disease and Treatment is an international, peerreviewed journal of clinical therapeutics and pharmacology focusing on concise rapid reporting of clinical or pre-clinical studies on a range of neuropsychiatric and neurological disorders. This journal is indexed on PubMed Central, the 'PsycINFO' database and CAS, and is the official journal of The International Neuropsychiatric Association (INA). The manuscript management system is completely online and includes a very quick and fair peer-review system, which is all easy to use. Visit http://www.dovepress.com/testimonials.php to read real quotes from published authors. 